\title{
Preoperative FDG PET/CT in breast cancer patients: where are we going?
}

\author{
Laura Gilardi • Concetta De Cicco • Giovanni Paganelli
}

Published online: 14 September 2012

(C) Springer-Verlag 2012

Breast cancer remains the commonest female malignancy in Western countries and the second leading cause of cancer mortality in women [1].

Accurate staging at the time of the initial diagnosis plays a major role in the choice of therapeutic modalities for an optimal management of these patients [2]. Breast cancer staging includes assessment of cancer spread to regional lymph nodes and also to distant sites. Being a whole-body procedure, PET/CT is able to assess all these data in a single test, providing morphological information and also evaluating the metabolic activity of the disease.

However, FDG PET/CT is not currently indicated for primary breast cancer diagnosis, mainly due to its poor spatial resolution. Indeed, diagnostic accuracy depends on primary breast tumour size as reported by Cermik et al. In this series the sensitivity of FDG PET to detect nonpalpable, small $(<10 \mathrm{~mm})$ invasive malignancies ranged from 53 to $63 \%$ for T1mic/T1a and T1b tumours, respectively [3]. In addition, PET imaging accuracy is affected by tumour histology: invasive lobular carcinomas are detected with less sensitivity than ductal carcinomas [4, 5]. Conversely, the detection of high intensity, focal FDG uptake in the breast has a strong positive value for cancer [6].

In practice the main contribution of PET in local tumour assessment consists in measuring FDG uptake by the standardized uptake value (SUV), which is useful to evaluate

This editorial commentary refers to the article http://dx.doi.org/10.1007/ s002259-012-2181-1.

L. Gilardi $\cdot$ C. De Cicco $\cdot$ G. Paganelli $(\bowtie)$

Division of Nuclear Medicine, European Institute of Oncology,

Via Ripamonti 435,

20141 Milan, Italy

e-mail: divisione.medicinanucleare@ieo.it early response to neoadjuvant therapy in those cases not submitted to surgery directly. Indeed, while morphological changes due to therapy activity are not detectable until 46 months of treatment, metabolic changes occur earlier and are assessable even after one or two cycles of systemic therapy [7, 8]. This allows the oncologist to anticipate surgery, if needed.

According to several studies FDG PET/CT could provide some important clinical and biological information about the disease aggressiveness [9-11], even if the degree of FDG uptake in the primary tumour has not proven to be an independent predictor of outcome $[12,13]$.

In addition to tumour size, the status of the axillary lymph nodes is the most reliable prognostic indicator for recurrence and survival in early breast cancer.

None of the current imaging procedures has sufficient sensitivity to substitute the sentinel node biopsy (SNB) in the histopathological evaluation of the axilla. In particular, $\mathrm{PET} / \mathrm{CT}$ showed poor sensitivity for axillary staging, with values as low as $20 \%$ in some series [14, 15]. This is especially true for breast cancer patients with very restricted disease spread to the axilla, because of the limited spatial resolution of the technique and the presence of few FDGavid cells in case of micrometastases.

Vinh-Hung et al. reconfirmed these data with their paper published in the present issue of the European Journal of Nuclear Medicine and Molecular Imaging. The authors retrospectively evaluated 104 patients, who underwent preoperative FDG PET/CT for breast cancer staging and surgery as part of planned primary therapy. The diagnostic utility of the preoperative PET scan in the assessment of axillary lymph node involvement was reported: among 63 PET node-negative patients, 26 were histopathological node-positive and among 41 PET node-positive patients, 36 were histopathological node-positive. These data confirm 
that preoperative PET scan is not adequate in the classification of lymph node involvement [16], but it can be useful in differentiating low versus high burden nodal disease [17].

A false-negative result generally represents a very small number of lymph node metastases, with very limited invasion of the lymphatic structures. On the contrary a nodepositive PET scan has high specificity and positive predictive value for axillary staging and indicates a higher disease spread to this region [18]. Therefore PET/CT could guide the choice of surgical treatments on the axilla. Direct axillary lymph node dissection (ALND), avoiding SNB, could be proposed in PET node-positive patients, while SNB actually remains the best staging procedure in PET nodenegative cases.

Increasing data suggest that surgical management of the axilla by SNB or ALND has no influence on recurrence-free and overall survival in all breast cancer patients. However, sample size and length of follow-up are substantially different among studies, so definitive conclusions are not available [19]. In this setting PET/CT could be mainly useful for its ability in differentiating low from high axillary involvement, and for the prognostic information it can provide.

Indeed, Vinh-Hung et al. found that PET positivity in axillary lymph nodes was the only unequivocal preoperative predictor of disease-free survival (DFS), overriding the other conventional prognostic factors and providing prognostic information second only to histological lymph node involvement [17]. Inoue et al. reported that the prognosis for breast cancer patients with high $\mathrm{SUV}_{\max }$ in the primary tumour and concomitant PET-positive axillary lymph nodes was significantly poorer than that of the other patients, with a 5-year DFS of 44.4 vs $96.8 \%$ [12]. Song et al. demonstrated that axillary lymph node $\mathrm{SUV}_{\max }$ on preoperative PET was an independent prognostic factor for disease recurrence in a population of 65 women with invasive ductal carcinoma [20].

$\mathrm{PET} / \mathrm{CT}$ is therefore standing out as a risk stratification modality in patients with breast tumours, as it could distinguish aggressive from indolent forms of cancer. This evaluation may become more important in the future, in case axillary surgery is not performed and no prognostic information is available [21]. Consequently PET/CT could provide the basis for a better management of breast cancer patients, avoiding overtreatment in low-risk cases.

PET/CT can also define the real aim of the therapeutic strategy in newly diagnosed breast cancer. Indeed, as a whole-body modality, it is able to detect unknown distant metastases, changing the therapeutic purpose from curative to palliative.

FDG PET/CT performs better than conventional imaging to demonstrate occult metastases in breast cancer patients [22-24]. It is a valuable tool in locally advanced breast cancer, but also in early-stage disease [25-28]. In particular, Groheux et al. demonstrated that PET/CT had a non-negligible yield in patients with stage IIB and primary operable stage IIIA breast cancer. In these patients with T3 N0, T2 N1 or T3 N1 disease the overall yield was $13 \%$ with a change in therapeutic management due to the finding of N3 disease or distant metastases. Even 2 of 36 patients with stage IIA disease were upstaged due to the discovery of internal mammary lymph node (1 patient) and contralateral supraclavicular and mediastinal nodal disease (1 patient) [26]. Extra-axillary lymph node involvement was also detected in almost one third of stage IIIII breast cancer patients in the study of Aukema et al. PET/CT upgraded the TNM stage in $17 \%(10 / 60)$ of the patients, leading to a change in the radiotherapy plan in $12 \%(7 / 60)$ [29].

The above-mentioned studies indicate that FDG PET/CT imaging is applicable to a patient population with a wide range of tumour stages, from T1 to T4 carcinomas. Patients with more aggressive and FDG-avid histopathological subtypes are more likely to have distant metastases, but also patients not fulfilling these criteria could present a stage IV disease at the initial diagnosis.

Breast cancer is indeed an heterogeneous disease in terms of histology, dissemination modality, therapeutic response and prognosis. The tumours can be classified into subtypes distinguished by pervasive difference in their gene expression patterns [30, 31]. The decision to perform an FDG PET/CT scan in the initial evaluation of patients with breast cancer should probably take into account these biological differences.

Actually some uncertainties remain about the exact characteristics (clinical stage and histopathological features) of newly diagnosed breast cancer for which PET/CT should be systematically performed with a favourable cost-effectiveness balance. Moreover, standard characteristics of the equipment to be used need a clear definition; a combination of state-ofthe-art PET/CT plus a dedicated breast PET device with a single FDG injection could be indicated. Targeted prospective studies with a large number of patients are therefore necessary to better define these points.

\section{References}

1. Siegel R, Naishadham D, Jemal A. Cancer statistics, 2012. CA Cancer J Clin 2012;62:10-29.

2. Norum J, Andreassen T. Screening for metastatic disease in newly diagnosed breast cancer patients. What is cost-effective? Anticancer Res 2000;20:2193-6.

3. Cermik TF, Mavi A, Basu S, Alavi A. Impact of FDG PET on the preoperative staging of newly diagnosed breast cancer. Eur J Nucl Med Mol Imaging 2008;35:475-83.

4. Avril N, Rosé CA, Schelling M, Dose J, Kuhn W, Bense S, et al. Breast imaging with positron emission tomography and fluorine-18 fluorodeoxyglucose: use and limitations. J Clin Oncol 2000;18:3495502.

5. Avril N, Menzel M, Dose J, Schelling M, Weber W, Jänicke F, et al. Glucose metabolism of breast cancer assessed by $18 \mathrm{~F}-\mathrm{FDG}$ 
PET: histologic and immunohistochemical tissue analysis. J Nucl Med 2001;42:9-16.

6. Kang BJ, Lee JH, le Yoo R, Kim SH, Choi JJ, Jeong SH, et al. Clinical significance of incidental finding of focal activity in the breast at 18F-FDG PET/CT. AJR Am J Roentgenol 2011;197:341-7.

7. Berriolo-Riedinger A, Touzery C, Riedinger J-M, Toubeau M, Coudert B, Arnould L, et al. [18F]FDG-PET predicts complete pathological response of breast cancer to neoadjuvant chemotherapy. Eur J Nucl Med Mol Imaging 2007;34:1915-24.

8. Duch J, Fuster D, Muñoz M, Fernández PL, Paredes P, Fontanillas $\mathrm{M}$, et al. 18F-FDG PET/CT for early prediction of response to neoadjuvant chemotherapy in breast cancer. Eur J Nucl Med Mol Imaging 2009;36:1551-7.

9. Sanli Y, Kuyumcu S, Ozkan ZG, Ișık G, Karanlik H, Guzelbey B, et al. Increased FDG uptake in breast cancer is associated with prognostic factors. Ann Nucl Med 2012;26:345-50.

10. Kim BS, Sung SH. Usefulness of 18F-FDG uptake with clinicopathologic and immunohistochemical prognostic factors in breast cancer. Ann Nucl Med 2012;26:175-83.

11. Ueda S, Tsuda H, Asakawa H, Shigekawa T, Fukatsu K, Kondo N, et al. Clinicopathological and prognostic relevance of uptake level using 18F-fluorodeoxyglucose positron emission tomography/ computed tomography fusion imaging (18F-FDG PET/CT) in primary breast cancer. Jpn J Clin Oncol 2008;38:250-8.

12. Inoue T, Yutani K, Taguchi T, Tamaki Y, Shiba E, Noguchi S. Preoperative evaluation of prognosis in breast cancer patients by [18F]2-deoxy-2-fluoro-D-glucose-positron emission tomography. J Cancer Res Clin Oncol 2004;130:273-8.

13. De Cicco C, Gilardi L, Botteri E, Fracassi SLV, Di Dia GA, Botta $\mathrm{F}$, et al. Is [(18)F] fluorodeoxyglucose uptake by the primary tumor a prognostic factor in breast cancer? Breast 2012. doi:10.1016/ j.breast.2012.05.009.

14. Wahl R, Siegel BA, Coleman RE, Gatsonis CG, PET Study Group. Prospective multicenter study of axillary nodal staging by positron emission tomography in breast cancer: a report of the staging breast cancer with PET Study Group. J Clin Oncol 2004;22:277-85.

15. Monzawa S, Adachi S, Suzuki K, Hirokaga K, Takao S, Sakuma T, et al. Diagnostic performance of fluorodeoxyglucose-positron emission tomography/computed tomography of breast cancer in detecting axillary lymph node metastasis: comparison with ultrasonography and contrast-enhanced CT. Ann Nucl Med 2009;23:855-61.

16. Veronesi U, De Cicco C, Galimberti E, Fernandez JR, Rotmensz $\mathrm{N}$, Viale $\mathrm{G}$, et al. A comparative study on the value of FDG-PET and sentinel node biopsy to identify occult axillary metastases. Ann Oncol 2007;18:473-8.

17. Vinh-Hung V, Everaert H, Lamote J, Voordeckers M, van Parijs H, Vanhoeij M, et al. Diagnostic and prognostic correlates of preoperative FDG PET for breast cancer. Eur J Nucl Med Mol Imaging 2012. doi:10.1007/s00259-012-2181-1.

18. Kumar R, Zhuang H, Schnall M, Conant E, Damia S, Weinstein S, et al. FDG PET positive lymph nodes are highly predictive of metastasis in breast cancer. Nucl Med Commun 2006;27:231-6.
19. Gerber B, Heintze K, Stubert J, Dieterich M, Hartmann S, Stachs A, et al. Axillary lymph node dissection in early-stage invasive breast cancer: is it still standard today? Breast Cancer Res Treat 2011;128:613-24.

20. Song BI, Lee SW, Jeong SY, Chae YS, Lee WK, Ahn BC, et al. $18 \mathrm{~F}-\mathrm{FDG}$ uptake by metastatic axillary lymph nodes on pretreatment PET/CT as a prognostic factor for recurrence in patients with invasive ductal breast cancer. J Nucl Med 2012. doi:10.2967/ jnumed.111.098640.

21. Giuliano AE, Hunt KK, Ballman KV, Beitsh PD, Whitworth PW, Blumencranz PW, et al. Axillary dissection vs no axillary dissection in women with invasive breast cancer and sentinel node metastasis: a randomized clinical trial. JAMA 2011;305:569-75.

22. Mahner S, Schirrmacher S, Brenner W, Jenicke L, Habermann CR, Avril N, et al. Comparison between positron emission tomography using 2-[fluorine-18]fluoro-2-deoxy-D-glucose, conventional imaging and computed tomography for staging of breast cancer. Ann Oncol 2008;19:1249-54.

23. Niikura N, Costelloe CM, Madewell JE, Hayashi N, Yu T-K, Liu J, et al. FDG-PET/CT compared with conventional imaging in the detection of distant metastases of primary breast cancer. Oncologist 2011;16:1111-9.

24. Koolen BB, Vrancken Peeters MJTFD, Aukema TS, Vogel WV, Oldenburg HAS, van der Hage JA, et al. 18F-FDG PET/CT as a staging procedure in primary stage II and III breast cancer: comparison with conventional imaging techniques. Breast Cancer Res Treat 2012;131:117-26.

25. Fuster D, Duch J, Paredes P, Velasco M, Muñoz M, Santamaría G, et al. Preoperative staging of large primary breast cancer with $[18 \mathrm{~F}]$ fluorodeoxyglucose positron emission tomography/computed tomography compared with conventional imaging procedures. J Clin Oncol 2008;26:4746-51.

26. Segaert I, Mottaghy F, Ceyssens S, De Wever W, Stroobants S, Van Ongeval C, et al. Additional value of PET-CT in staging of clinical stage IIB and III breast cancer. Breast J 2010;16:617-24.

27. Groheux D, Giacchetti S, Espié M, Vercellino L, Hamy A-S, Delord M, et al. The yield of 18F-FDG PET/CT in patients with clinical stage IIA, IIB, or IIIA breast cancer: a prospective study. J Nucl Med 2011;52:1526-34.

28. Bernsdorf M, Berthelsen AK, Wielenga VT, Kroman N, Teilum D, Binderup T, et al. Preoperative PET/CT in early-stage breast cancer. Ann Oncol 2012;23:2277-82. doi:10.1093/annonc/mds002.

29. Aukema TS, Straver ME, Vrancken Peeters MJTFD, Russell NS, Gilhuijs KGA, Vogel WV, et al. Detection of extra-axillary lymph node involvement with FDG PET/CT in patients with stage II-III breast cancer. Eur J Cancer 2010;46:3205-10.

30. Perou CM, Sørlie T, Eisen MB, van de Rijn M, Jeffrey SS, Rees $\mathrm{CA}$, et al. Molecular portraits of human breast tumours. Nature 2000;406:747-52.

31. Parker JS, Mullins M, Cheang MCU, Leung S, Voduc D, Vickery T, et al. Supervised risk predictor of breast cancer based on intrinsic subtypes. J Clin Oncol 2009;27:1160-7. 